University of Wollongong

Research Online

Australian Institute for Innovative Materials -

Papers

Australian Institute for Innovative Materials

$1-1-2018$

Insight into the Synergistic Effect on Selective Adsorption for Heavy Metal Ions by a Polypyrrole/TiO2Composite

Jie Chen

Xian Jiaotong University

Mengting Yu

Xian Jiaotong University

Caiyun Wang

University of Wollongong, caiyun@uow.edu.au

Jiangtao Feng

Xian Jiaotong University

Wei Yan

Xian Jiaotong University

Follow this and additional works at: https://ro.uow.edu.au/aiimpapers

Part of the Engineering Commons, and the Physical Sciences and Mathematics Commons

Research Online is the open access institutional repository for the University of Wollongong. For further information contact the UOW Library: research-pubs@uow.edu.au 


\title{
Insight into the Synergistic Effect on Selective Adsorption for Heavy Metal Ions by a Polypyrrole/TiO2Composite
}

\author{
Abstract \\ Polymer/metal oxide composites are promising candidates for the treatment of water pollution. \\ Adsorption selectivity as well as a large adsorption capacity are two key factors for treating wastewater \\ containing multiple ions. Herein, a PPy+/TiO2(O-) composite with a heterojunction structure was first \\ discovered to have novel selectivity toward heavy metal ions. An interesting self-doping nature of TiO2(0-) \\ together with S042-for PPy+was reported. This interesting structure contributed to an impressive \\ selective adsorption capability with an ascending order of $\mathrm{Zn2}+>\mathrm{Pb} 2+\gg \mathrm{Cu} 2+$ in a ternary ion system, \\ where the adsorption for $\mathrm{Cu} 2+$ could be almost suppressed. Through the designed adsorption \\ experiments and characterization techniques including Fourier transform infrared, thermogravimetric \\ analysis, and X-ray photoelectron spectroscopy, a universal synergistic mechanism for PPy+/TiO2(O-) \\ composite was first proposed and confirmed. The doping and dedoping of metal oxide (dopant) from the \\ polymer dictates the adsorption selectivity, where the selectivity is determined by the interaction between \\ TiO2and heavy metal ions. This work may provide some useful guidelines for designing adsorbents with \\ selectivity toward specific heavy metal ions.

\section{Disciplines} \\ Engineering | Physical Sciences and Mathematics

\section{Publication Details} \\ Chen, J., Yu, M., Wang, C., Feng, J. \& Yan, W. (2018). Insight into the Synergistic Effect on Selective \\ Adsorption for Heavy Metal lons by a Polypyrrole/TiO2Composite. Langmuir: the ACS journal of surfaces \\ and colloids, 34 (34), 10187-10196.
}




\section{Insight into the synergistic effect on selective adsorption for heavy metal ions by a polypyrrole/ $\mathrm{TiO}_{2}$ composite}

Jie Chen ${ }^{1}$, Mengting Yu ${ }^{1}$, Caiyun Wang ${ }^{2}$, Jiangtao Feng ${ }^{1 *}$, Wei Yan ${ }^{1 *}$

1 Department of Environmental Science and Engineering, State Key Laboratory of Multiphase Flow in Power Engineering, Xi'an Jiaotong University, Xi'an 710049, P.R. China

2 ARC Centre of Excellence for Electromaterials Science, Intelligent Polymer Research Institute, AIIM Facility, University of Wollongong, North Wollongong, NSW 2500, Australia

*Corresponding authors:

E-mail addresses: fjtes@xjtu.edu.cn (J. Feng), yanwei@mail.xjtu.edu.cn (W. Yan).

Table of Contents (TOC)/Abstract Art

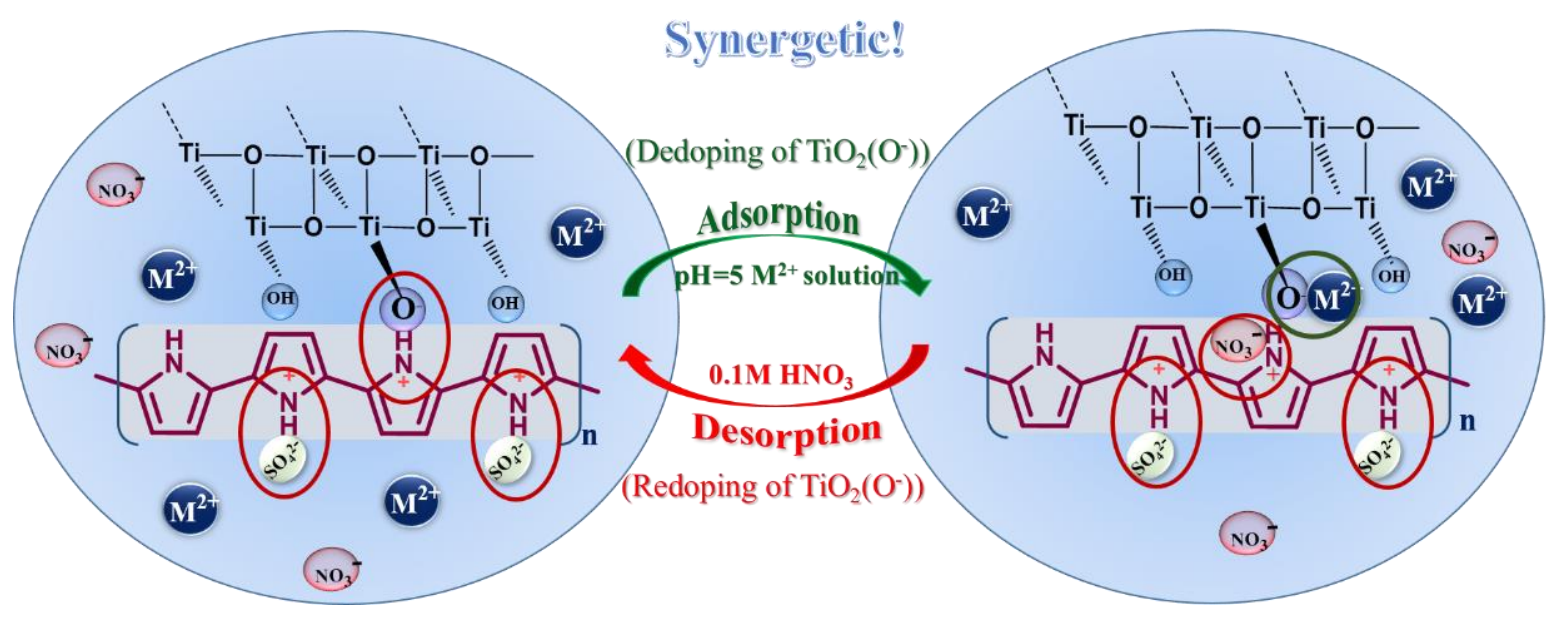




\section{Abstract}

Polymer/metal oxide composites are prime candidates for the treatment of water pollution. For this purpose, it is key that the composite has adsorption selectivity, as well as a large adsorption capacity, which is especially important for wastewater containing multiple ions. Herein, a $\mathrm{PPy}^{+} / \mathrm{TiO}_{2}\left(\mathrm{O}^{-}\right)$ composite with a heterojunction structure was first discovered to have novel selectivity towards heavy metal ions. An interesting self-doping nature of $\mathrm{TiO}_{2}\left(\mathrm{O}^{-}\right)$together with $\mathrm{SO}_{4}{ }^{2-}$ for $\mathrm{PPy}^{+}$was reported. This interesting structure contributed to an impressive selective adsorption capability with an ascending order of $\mathrm{Zn}^{2+}>\mathrm{Pb}^{2+}>>\mathrm{Cu}^{2+}$ in a ternary ion system, where the adsorption for $\mathrm{Cu}^{2+}$ could be almost suppressed. Through the designed adsorption experiments and characterization including FTIR, TGA and XPS, a universal synergistic mechanism for the polymer/metal oxide composite was first proposed and confirmed. We suggest that the doping and dedoping of the metal oxide (dopant) from the polymer dictates the special adsorption selectivity of the composite, where the selectivity is determined by the interaction between $\mathrm{TiO}_{2}$ and heavy metal ions. This mechanism we proposed may provide some guidelines for designing adsorbents with selectivity towards specific heavy metal ions.

\section{Introduction}

Water pollution with heavy metal ions produced from the industry of mining, painting, car radiator manufacturing, batteries, and metal plating etc. is increasingly becoming a significant environmental problem ${ }^{1}$. Adsorption is regarded as a prospective treatment for heavy metal ions due to its low cost, simplicity and easy operational conditions, attracting wide attention from academic and industrial $\operatorname{areas}^{2-4}$. However, several kinds of heavy metal ions can co-exist in natural and industrial water environments. These ions compete for adsorption sites, leading to a decreased adsorption capacity ${ }^{3,5}$ 
Therefore, in addition to having a large adsorption capacity, we have been concerned about the selective adsorption ability of the adsorbent, which is especially important in the treatment of wastewater.

Another important aspect to consider is synergistic phenomena, which can be found everywhere, from physics to chemistry. Many interesting properties such as solubility and hydrophilicity of a composite can also be introduced by the synergistic properties of the combined material ${ }^{6-10}$. Thus, the design and application of polymer/metal oxide composite have increasingly been the subject of investigation in recent years due to their interesting synergistic effect between polymer and metal oxide ${ }^{6-11}$. J. Yang et al. ${ }^{11}$ synthesized a lignosulfonate-graphene oxide-polyaniline (LS-GO-PANi) nanocomposite for Pb(II) adsorption, and deduced that the synergistic phenomena between PANi and LS-GO may play a key role in the adsorption. J.Y. Huang et al. $^{7}$ prepared polyimide (PI)/silica powders for heavy metal ion removal. The synergistic effect between silica and polyimide lead to the improvement of the adsorption capacity and affinity. Even though composite synthesis for adsorption purposes is a subject undergoing intense study, the mechanism of the synergistic effects in these studies was only inferred without detailed investigation. The exact mechanism is still unknown. It is important to determine a universal mechanism for the synergistic effects to provide a guideline to design an adsorbent with improved adsorption capacity. Therefore, a detailed investigation on the synergistic effect of a composite should be extensively conducted.

To solve this problem, PPy and $\mathrm{TiO}_{2}$ were selected for the study of synergistic effects. Specifically, the conjugated polymer polypyrrole (PPy) is a promising candidate due to its novel conjugated structure 
and redox properties, offering a rich electrochemical chain that undergoes ion doping and dedoping on the pyrrolylium nitrogen (Scheme $\boldsymbol{S} \mathbf{1}$ ), which may additionally experience interaction and synergistic effect with metal oxides ${ }^{12-16}$. Metal oxides have demonstrated a selective adsorption affinity to some heavy metal ions such as Mn oxides toward $\mathrm{Cu}(\mathrm{II})$, Fe oxides to $\mathrm{Pb}(\mathrm{II})$, while $\mathrm{Zn}$ (II) can be specifically attracted by Si oxides ${ }^{17}$. This could lead to synergistic effects between PPy and metal oxides and is expected to produce a material with selective ion-uptake. Even though there has been some published literature concerning PPy/metal oxides for heavy metal adsorption ${ }^{18-21}$, there have been limited reports on adsorption in multiple metal ions solutions to take the selectivity of adsorption into consideration.

Herein, the overall aim of this paper is to gain insight into the synergistic mechanism between polymer and metal oxide for the selective adsorption of metal ions. The redox states, structure, textural properties and interaction between PPy and $\mathrm{TiO}_{2}$ were carefully characterized. Various adsorption experiments, including kinetic, single and multi-component isotherms, were designed and conducted to reveal the individual and competitive adsorption properties for $\mathrm{Pb}(\mathrm{II}), \mathrm{Zn}(\mathrm{II})$ and $\mathrm{Cu}(\mathrm{II})$. Finally, the mechanism of the synergistic effect between PPy and $\mathrm{TiO}_{2}$ was first proposed and supported by $\mathrm{pH}$ experiments, as well as technical instruments including FT-IR, TGA and XPS. The novelty of this work is obtaining a new discovery and a general understanding of a mechanism for the synergetic effect between a polymer and metal oxide and on the selective adsorption of heavy metal ions for the removal of pollutants from waste water. The mechanism proposed may be of great value in aiding the design of adsorbents with selectivity towards certain heavy metal ions.

\section{Experimental}

\subsection{Materials}


The chemicals used in this study were of analytical grade and were purchased from Sinopharm Chemical Reagent Co., Ltd. Pyrrole was distilled twice and stored in the dark prior to use. The standard heavy metal solutions were prepared from $\mathrm{Pb}\left(\mathrm{NO}_{3}\right)_{2}, \mathrm{Cu}\left(\mathrm{NO}_{3}\right)_{2} \cdot 3 \mathrm{H}_{2} \mathrm{O}$ and $\mathrm{Zn}\left(\mathrm{NO}_{3}\right)_{2} \cdot 6 \mathrm{H}_{2} \mathrm{O}$, respectively with deionized water.

\subsection{Synthesis of the $\mathrm{PPy}, \mathrm{TiO}_{2}$ and $\mathrm{PPy} / \mathrm{TiO}_{2}$ composite}

The PPy/TiO 2 composite doped with $\mathrm{H}_{2} \mathrm{SO}_{4}$ was synthesized using in-situ chemical oxidative polymerization ${ }^{22}$. The $\mathrm{TiO}_{2}$ was prepared through sol-gel method. The volume ratio of 5:2 of npropanol and tetrabutyl titanate were carefully charged into $200 \mathrm{~mL}, 0.24 \mathrm{~mol} / \mathrm{L}_{\text {of }} \mathrm{H}_{2} \mathrm{SO}_{4}$ solution and stirred for $24 \mathrm{~h}$. The formed $\mathrm{TiO}_{2}$ suspension solution was subsequently cooled to $5{ }^{\circ} \mathrm{C}$ in the dark before $0.675 \mathrm{~mL}$ of pyrrole monomer was added. Then $25 \mathrm{~mL}, 1.0 \mathrm{~mol} / \mathrm{L}$ of $\mathrm{FeCl}_{3}$ solution was dosed dropwise to the solution and stirred for another $24 \mathrm{~h}$ in dark. Finally, the obtained dark composite was filtrated and washed with $0.01 \mathrm{~mol} / \mathrm{L} \mathrm{H}_{2} \mathrm{SO}_{4}$ solution several times to remove the oligomer and other impurities. For comparison, pure $\mathrm{TiO}_{2}$ was prepared using the same procedure but without adding pyrrole monomer and $\mathrm{FeCl}_{3}$; pure PPy was synthesized using the same procedure but without adding $\mathrm{TiO}_{2}$.

\subsection{Characterization}

The Fourier transform infrared spectra (FT-IR) of $\mathrm{PPy}, \mathrm{TiO}_{2}$ and the $\mathrm{PPy} / \mathrm{TiO}_{2}$ composite were performed on a BRUKER TENSOR 37 FT-IR spectrometer by the KBr pellet method over a range of 4000-400 $\mathrm{cm}^{-1}$. The X-ray photoelectron spectroscopy (XPS) spectra were determined on a Kratos Axis Ultra DLD, with an Al monochromatic X-ray source (1486.71 eV). All binding energies (BEs) were referenced to the $\mathrm{C} 1 \mathrm{~s}$ hydrocarbon peak at $284.6 \mathrm{eV}$. The zeta potential investigations were conducted on a Malvern Zetasizer Nano ZS90. The thermogravimetric (TG) analysis was investigated 
on a Setaram Labsys Evo in $\mathrm{N}_{2}$ flow, and the heating rate was $10^{\circ} \mathrm{C} / \mathrm{min}$. X-ray diffraction (XRD) patterns were acquired on an X'Pert PRO Diffractometer with wavelength of $1.5406 \AA(\mathrm{Cu}-\mathrm{K} \alpha$ radiation method) over a range of 10-80 degrees. The $\mathrm{N}_{2}$ adsorption and desorption isotherms were recorded on a Builder SSA-4200 at 77K and the specific surface area, total pore volume and average pore radius were calculated using a Builder analysis software. Scanning electron microscopy (SEM) was performed on a JSM-6700F. Transmission electron microscopy images (TEM) were recorded on a JEM model 2100 electron microscope. The concentrations of heavy metal ions were determined using an inductive coupled plasma emission spectrometer (ICPE-9000, Shimadzu).

\subsection{Adsorption experiments}

In all adsorption experiments, the dose of adsorbent was $2 \mathrm{~g} / \mathrm{L}$, and the volume of heavy metal solution was $20 \mathrm{~mL}$. All experiments were conducted in a shaker at a constant temperature, and the agitation speed was kept at $200 \mathrm{rpm}$. To avoid the influence of precipitation of metal ions on the adsorption, the solution $\mathrm{pH}$ was kept at 5 .

In the kinetic experiment, the composite was dosed in $400 \mathrm{mg} / \mathrm{L} \mathrm{Pb}^{2+}, \mathrm{Zn}^{2+}$ and $\mathrm{Cu}^{2+}$ solutions, respectively, with various contact times $(0-180 \mathrm{~min})$. In the single ion isotherm investigations, the composite was dosed in the $\mathrm{Pb}^{2+}, \mathrm{Zn}^{2+}$ and $\mathrm{Cu}^{2+}$ solutions with various initial concentration at 15,25 , $45^{\circ} \mathrm{C}$, respectively for $3 \mathrm{~h}$. For $\mathrm{Pb}^{2+}$ adsorption, the initial concentration was $100,200,300,400,600$, $800 \mathrm{mg} / \mathrm{L}$, respectively; while for $\mathrm{Zn}^{2+}$ and $\mathrm{Cu}^{2+}$ adsorption, the initial concentration was $10,50,100$, $200,400,600 \mathrm{mg} / \mathrm{L}$, respectively. In the multiple ion isotherm investigations, the composite was dosed in the $\mathrm{Pb}^{2+}, \mathrm{Zn}^{2+}$ and $\mathrm{Cu}^{2+}$ mixed solution with initial concentration of $50,100,200,300,400 \mathrm{mg} / \mathrm{L}$, respectively at $25^{\circ} \mathrm{C}$ for $3 \mathrm{~h}$. In the $\mathrm{pH}$ experiment, the experiment was conducted in the solutions with 
initial $\mathrm{pH}$ from 1 to 5 , respectively with an initial heavy metal ion concentration of $200 \mathrm{mg} / \mathrm{L}$ for $3 \mathrm{~h}$. The $\mathrm{pH}$ used was adjusted using $\mathrm{HNO}_{3}$ and $\mathrm{NaOH}$ solution concentrated (Caution! The $\mathrm{HNO}_{3}$ and $\mathrm{NaOH}$ solutions are highly corrosive!).

The adsorption capacity and recycle efficiency was calculated as follows:

$Q_{e}=\frac{\left(C_{0}-C_{e}\right) V}{m}$,

Recycle efficiency $=\frac{Q_{e, n}}{Q_{e, 0}} \times 100 \%$

where $Q_{e}(\mathrm{mg} / \mathrm{g})$ is the equilibrium adsorption capacity; $C_{0}$ and $C_{e}(\mathrm{mg} / \mathrm{L})$ are the initial and equilibrium concentrations of heavy metal ions, respectively; $m(\mathrm{~g})$ is the weight of adsorbent; $V(\mathrm{~L})$ is the solution volume; $Q_{e, n}$ represents the adsorption capacity at $\mathrm{n}$ cycle, while $Q_{e, 0}$ represents the adsorption capacity before the recycle.

\section{Results and discussion}

\subsection{Characterization}

The structure of PPy/TiO 2 composite was illuminated by the FT-IR spectra shown in Fig.S1, and the main characteristic bands were listed in Table $\boldsymbol{S} \mathbf{1}$. For comparison, the spectra of $\mathrm{TiO}_{2}$ and $\mathrm{PPy}$ were also obtained. $\mathrm{TiO}_{2}$ shows only two broad peaks at 3419 and $400-700 \mathrm{~cm}^{-1}$. After being coated with PPy, the spectrum of the composite clearly exhibits the combination of the typical characteristic peaks assigned to PPy $\left(1551,1457,1317\right.$ and $\left.1056 \mathrm{~cm}^{-1}\right)$ and $\mathrm{TiO}_{2}\left(400-700 \mathrm{~cm}^{-1}\right)$, evidencing the successful synthesis of the $\mathrm{PPy} / \mathrm{TiO}_{2}$ composite. In addition, the presence of a strong peak situated at $1056 \mathrm{~cm}^{-1}$ which was ascribed to $\mathrm{C}_{\beta}-\mathrm{H}$ suggests an $\alpha-\alpha$ linking and regular polymerization of PPy ${ }^{16}$. Another dopant ion $\mathrm{SO}_{4}{ }^{2-}$ was also detected. However, it is noticeable that the peaks assigned to hydroxyl at 3419 and $1629 \mathrm{~cm}^{-1}$ in the spectrum of $\mathrm{TiO}_{2}$ and those for Py ring $\left(1524,1442,1284\right.$ and $\left.1025 \mathrm{~cm}^{-1}\right)$ in 
the spectrum of PPy shift to lower or higher wavenumbers, confirming the conclusion from the DFT calculations $^{23}$ that PPy is p-type semiconducting polymer, which donates its electron cloud density to $\mathrm{TiO}_{2}$, making $\mathrm{TiO}_{2}$ to be an n-type material in the $\mathrm{PPy} / \mathrm{TiO}_{2}$ composite. Therefore, following the DFT and the FT-IR results from $\mathrm{PPy} / \mathrm{TiO}_{2}$ composite, we proposed for the first time that $\mathrm{TiO}_{2}$ should be a dopant, acting through the hydroxyl to dope and undergo charge-transfer (CT) interactions with PPy in the $\mathrm{PPy} / \mathrm{TiO}_{2}$ system. The CT interaction model between $\mathrm{PPy}$ and $\mathrm{TiO}_{2}$ proposed herein (Scheme 1) may well explain the mechanism of the synergistic adsorption between $\mathrm{PPy}$ and $\mathrm{TiO}_{2}$ and the selective adsorption for heavy metal ions discussed in the later sections.

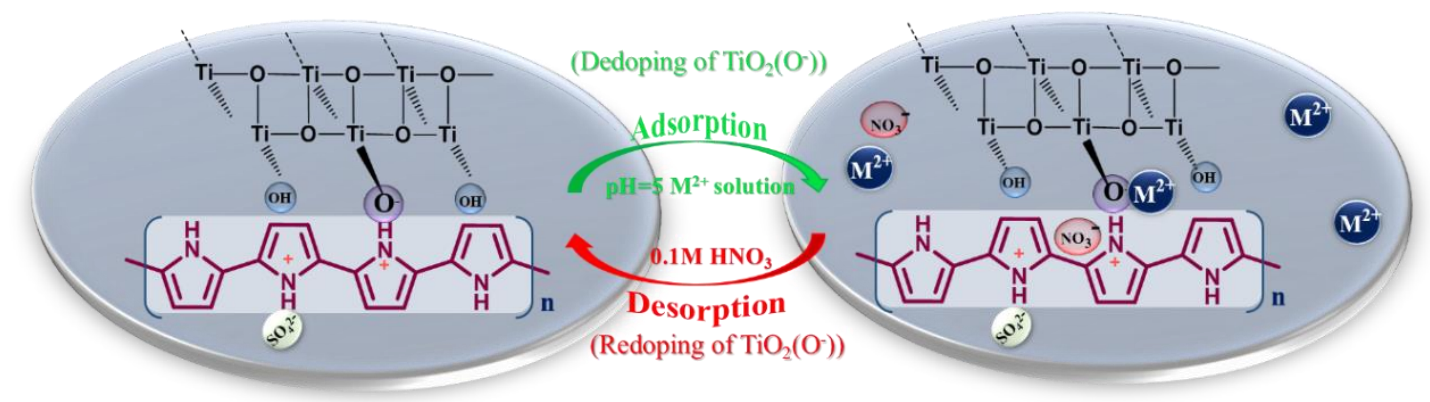

Scheme 1 The synergistic adsorption between $\mathrm{PPy}$ and $\mathrm{TiO}_{2}$ in the $\mathrm{PPy} / \mathrm{TiO}_{2}$ composite for the selective adsorption for heavy metal ions.

The N 1s XPS spectra shown in Fig.1 also confirm the PPy p-type doping state $\left(\mathrm{PPy}^{+}\left(\mathrm{X}^{-}\right)\right)$. It can be clearly deconvoluted into two peaks, which reveals the presence of a secondary component at 401.3 $\mathrm{eV}$ attributed to the positively charged nitrogen $\left(-\mathrm{N}^{+}-\right)$and a major component at $399.9 \mathrm{eV}$ for the pyrrolylium nitrogen (-NH-) ${ }^{16}$. It also verified that PPy was completely in its oxidation state. In addition, the proportion of positively charged nitrogen in the composite is calculated to be $31.2 \%$ according to the peak area, suggesting that almost $31.2 \%$ of the PPy are doped ${ }^{16}$. This doping feature is also confirmed by zeta-potential investigation (Fig. 2). The $\mathrm{pH}$ of zero point charge $\left(\mathrm{pH}_{\mathrm{pzpc}}\right)$ of the 
composite was 10.3 , relatively close to that of PPy (10.4), indicating the positively charged nature of the pyrrolylium nitrogen ${ }^{13}$.
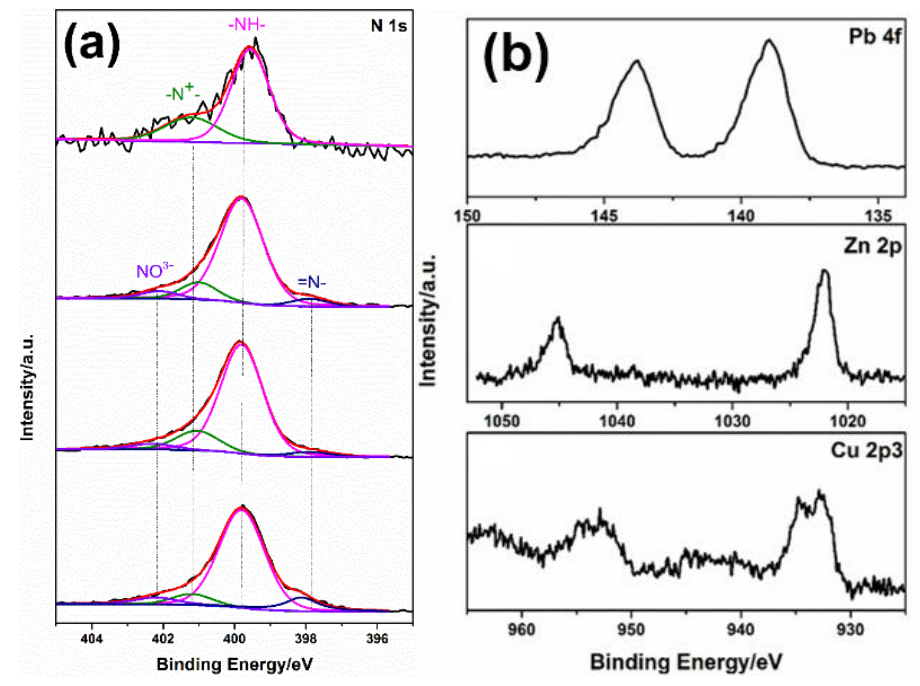

Fig. 1 (a)XPS N 1s core level spectra of the $\mathrm{PPy} / \mathrm{TiO}_{2}$ composite before and after adsorption of $\mathrm{Pb}^{2+}, \mathrm{Zn}^{2+}$ and $\mathrm{Cu}^{2+}$.

(b) $\mathrm{Pb} 4 \mathrm{f}, \mathrm{Zn} 2 \mathrm{p}, \mathrm{Cu} 2 \mathrm{p} 3$ core level spectra of the $\mathrm{PPy} / \mathrm{TiO}_{2}$ composite after adsorption of $\mathrm{Pb}^{2+}, \mathrm{Zn}^{2+}$ and $\mathrm{Cu}^{2+}$.

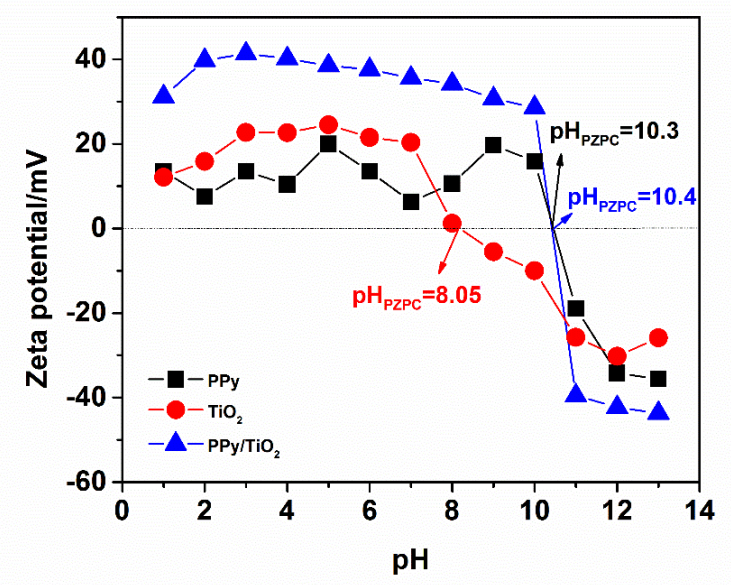

Fig. 2 Zeta potentials of $\mathrm{PPy}, \mathrm{TiO}_{2}$ and the $\mathrm{PPy} / \mathrm{TiO}_{2}$ composite in different $\mathrm{pH}$ and their $\mathrm{pH}$ of zero-point charge.

The CT interaction is effected by thermal degradation, and the $\operatorname{PPy}^{+}\left(\mathrm{X}^{-}\right)$begins to deprotonate and dedope to DP-PPy (deprotonated-PPy) when it is heated to a certain temperature ${ }^{24}$. Therefore, to further confirm the CT interaction in the composite between $\mathrm{TiO}_{2}, \mathrm{PPy}$ and dopant ions $\left(\mathrm{TiO}_{2}\left(\mathrm{O}^{-}\right)\right.$and $\mathrm{SO}_{4}{ }^{2-}$ ), thermogravimetric analysis (TGA) for $\mathrm{PPy}, \mathrm{TiO}_{2}$ and their composite was carried out and shown in Fig. S2. A three-stage process of $\mathrm{PPy} / \mathrm{TiO}_{2}$ in the thermal degradation was observed: the first 
weight loss from room temperature to $300{ }^{\circ} \mathrm{C}$ is assigned to the loss of hydroxyls and physically and chemically adsorbed water ${ }^{25}$; the second weight loss interval between $300{ }^{\circ} \mathrm{C}$ and $600{ }^{\circ} \mathrm{C}$ is ascribed to the loss of the doping ions $\mathrm{SO}_{4}{ }^{2-}$, which agrees with the results from Tan et al. ${ }^{24}$ that $\mathrm{PPy}^{+}\left(\mathrm{Cl}^{-}\right)$ started to lose the chloride species after having been heated slightly above $300{ }^{\circ} \mathrm{C}$; the final weight loss excess above $600{ }^{\circ} \mathrm{C}$ may be the further thermal decomposition of PPy. This weight loss process is also verified by the proportion loss of each component in the polymer as well as the composite from the TGA result (Table 1). The mass fraction of $\mathrm{SO}_{4}{ }^{2-}$ in the PPy chain is calculated to be about $18.73 \mathrm{w} / \mathrm{w} \%$ based on a doping level of 31.2\% from the XPS result (for calculation details please see the Supporting information), which fits well with the second weight loss interval of around $19.02 \mathrm{w} / \mathrm{w} \%$ in the TGA experiment. From the TGA study, more than $70 \%$ of the composite is $\mathrm{TiO}_{2}$, suggesting that the $\mathrm{TiO}_{2}$ may play a more important role in the adsorption.

Table 1 The proportion of each component in $\mathrm{PPy}, \mathrm{TiO}_{2}$ and the $\mathrm{PPy} / \mathrm{TiO}_{2}$ composite before and after adsorption.

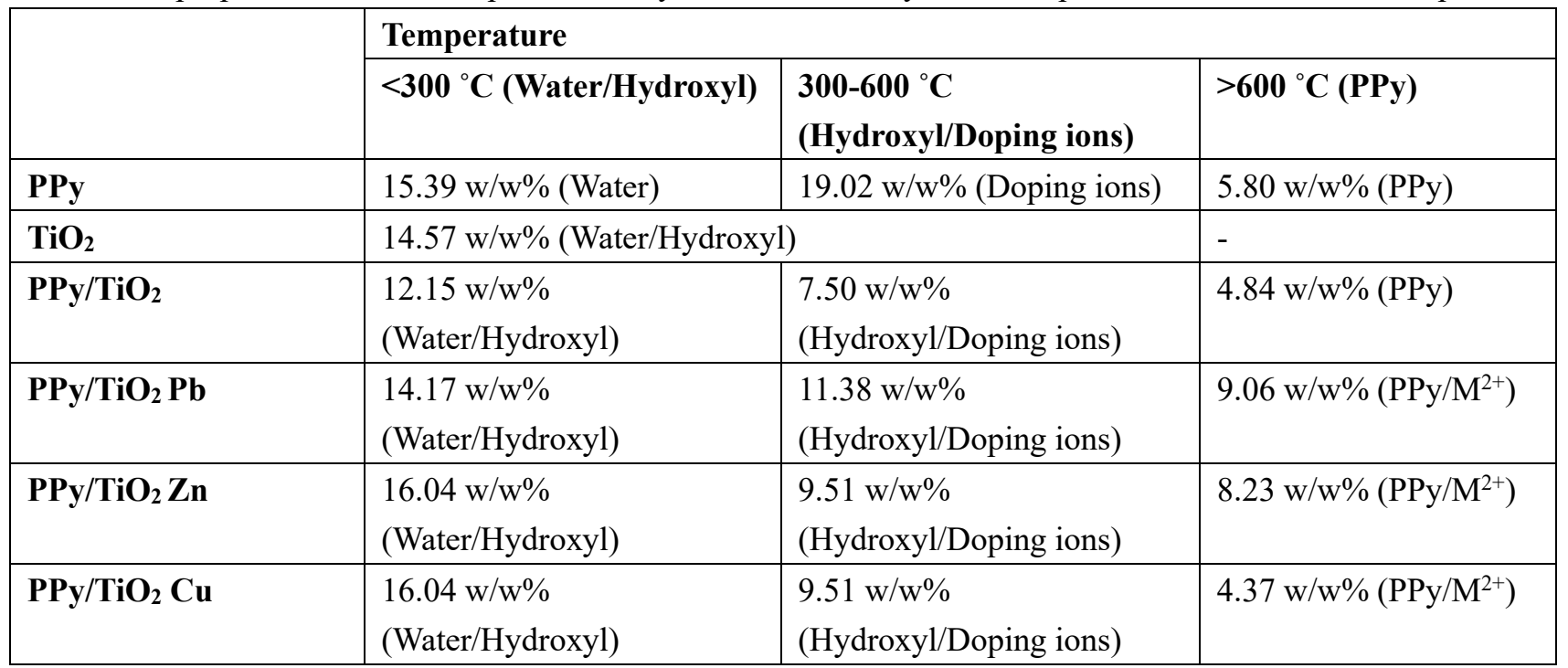

To better characterize the structure of $\mathrm{PPy} / \mathrm{TiO}_{2}$ composite, the XRD spectra of $\mathrm{PPy}, \mathrm{TiO}_{2}$ and $\mathrm{PPy} / \mathrm{TiO}_{2}$ composite were investigated and depicted in Fig. S3. Amorphous PPy and anatase $\mathrm{TiO}_{2}$ with 
characteristic peaks at $25.3^{\circ}, 37.8^{\circ}$ and $48.1^{\circ}$ can be confirmed ${ }^{26}$. After being covered with PPy, those three characteristic peaks almost disappeared and showed an amorphous shape, suggesting that the anatase $\mathrm{TiO}_{2}$ was completely covered by amorphous PPy ${ }^{27}$. This core-shell feature is also supported by the $\mathrm{N}_{2}$ adsorption-desorption experiment results (Fig. 3), and the textural parameters were listed in Table $\boldsymbol{S 2}$. The surface area and pore volume of $\mathrm{TiO}_{2}$ were extensively reduced after modification with PPy, which results from blocking by the $\mathrm{PPy}$, confirming the core-shell structure of $\mathrm{PPy} / \mathrm{TiO}_{2}$ composite. The core-shell structure was also confirmed by the SEM and TEM images shown in Fig. S4. The lattice fringe of $\mathrm{TiO}_{2}$ can be clearly observed in core of the composite, covered by an amorphous shell of PPy. The pore diameter of the composite is suggested to be around $6.45 \mathrm{~nm}$, which is much larger than the radius of the heavy metal ions $\left(0.97 \AA\right.$ for $\mathrm{Pb}^{2+}, 0.74 \AA$ for $\mathrm{Zn}^{2+}$ and $0.7 \AA$ for $\mathrm{Cu}^{2+}$ ), indicating that the ions can diffuse through the PPy to the $\mathrm{TiO}_{2}$ without resistance. It is also interesting to find that the isotherm of $\mathrm{TiO}_{2}$ was changed from Type II to Type I after PPy modification, further confirming the pore structure changes ${ }^{28}$. Nevertheless, this composite still shows a surface area of $140.0 \mathrm{~m}^{2} / \mathrm{g}$ providing sufficient sites for heavy metal adsorption.

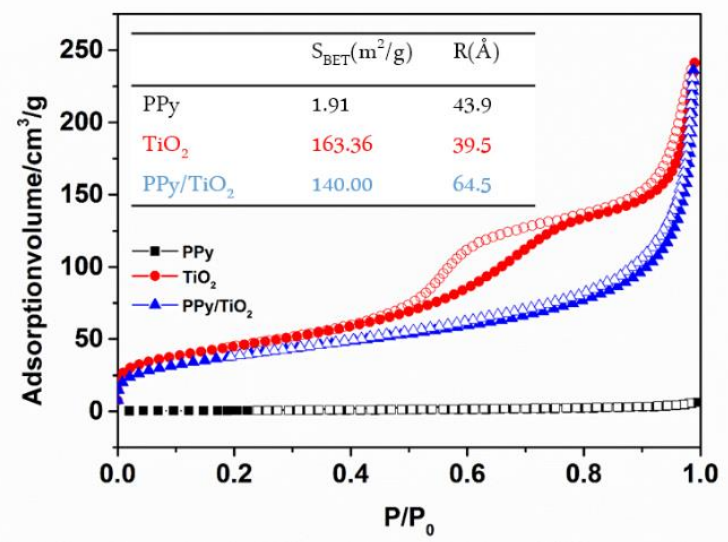

Fig. $3 \mathrm{~N}_{2}$ adsorption and desorption isotherms of $\mathrm{PPy}, \mathrm{TiO}_{2}$ and the $\mathrm{PPy} / \mathrm{TiO}_{2}$ composite.

\subsection{Adsorption investigation}


The detailed adsorption properties including kinetic, regeneration investigation and field sample analysis were carried out and are shown in Supporting information. They show that the $\mathrm{PPy} / \mathrm{TiO}_{2}$ composite is a promising adsorbent for adsorption engineering. The adsorption equilibrium can be achieved within $5 \mathrm{~min}$ for $\mathrm{Zn}^{2+}, 7 \mathrm{~min}$ for $\mathrm{Cu}^{2+}$ and $40 \mathrm{~min}$ for $\mathrm{Pb}^{2+}$, showing a novel fast adsorption. It can be recycled using $\mathrm{HNO}_{3}$ and $\mathrm{NaOH}$, which is low-cost and easily operational. It could also be effectively used in field conditions.

To understand the adsorption properties and selective adsorption nature, and to quantify the maximum adsorption capacity of the $\mathrm{PPy} / \mathrm{TiO}_{2}$ composite, isotherm studies at different temperatures in single and multi-component (ternary) systems were carried out (Fig. S5) ${ }^{29}$. The equilibrium experimental data are fitted using typical Langmuir ${ }^{30}$ and Freundlich ${ }^{31}$ models to illuminate the adsorption affinity and capacity, while using Dubinin-Radushkevich ${ }^{32}$ and Temkin ${ }^{33}$ models to estimate the adsorption free energy and heat. Relevant parameters and details about the models are summarized in Table 2 and Table $\boldsymbol{S 3}$. Considering the value of $\boldsymbol{R}^{2}$ and the accuracy of the $Q_{m}$ calculated, the equilibrium data can be well described by the Langmuir model, followed by the Freundlich and Temkin models in all cases, while the Dubinin-Radushkevich model is least able to predict the adsorption. Therefore, the discussions were mainly based on the Langmuir fitting results.

From the Langmuir model, the $\mathrm{PPy} / \mathrm{TiO}_{2}$ composite shows an outstanding maximum adsorption capacity up to $0.677 \mathrm{mmol} / \mathrm{g}$ for $\mathrm{Pb}^{2+}, 1.197 \mathrm{mmol} / \mathrm{g}$ for $\mathrm{Zn}^{2+}$ and $0.141 \mathrm{mmol} / \mathrm{g}$ for $\mathrm{Cu}^{2+}$, respectively in single ion solutions. Moreover, it is noticeable that the $Q_{m}$ in the $\mathrm{Pb}^{2+}$ and $\mathrm{Zn}^{2+}$ adsorption spectra increases steadily with temperature, which may result from the ionic exchange adsorption nature ${ }^{20}$. 
This phenomenon was also reported for other PPy-based adsorbents such as a PPy/chitin composite that adsorbed $\mathrm{Pb}^{2+}$ and $\mathrm{Cd}^{2+34}$ and a PPy/sawdust composite used for $\mathrm{Zn}^{2+}$ adsorption ${ }^{35}$. In contrast, the temperature did not obviously influence the $\mathrm{Cu}^{2+}$ adsorption. In this case, the adsorption of $\mathrm{Cu}^{2+}$ may have a different adsorption mechanism than $\mathrm{Pb}^{2+}$ and $\mathrm{Zn}^{2+}$.

Table 2 Single and multi-component adsorption isotherms parameters describing the adsorption of heavy metals $\left(\mathrm{Pb}^{2+}, \mathrm{Zn}^{2+}, \mathrm{Cu}^{2+}\right)$ onto $\mathrm{PPy} / \mathrm{TiO}_{2}$ composite, based on the Langmuir and Freundlich models.

\begin{tabular}{|c|c|c|c|c|c|c|c|c|c|c|c|c|c|c|c|c|c|}
\hline & & & \multicolumn{15}{|c|}{ Samples } \\
\hline & & & \multicolumn{9}{|c|}{$\mathrm{PPy} / \mathrm{TiO}_{2}$} & \multicolumn{3}{|l|}{ PPy } & \multicolumn{3}{|l|}{$\mathrm{TiO}_{2}$} \\
\hline & & & \multicolumn{3}{|l|}{$\mathbf{P b}$} & \multicolumn{3}{|l|}{$\mathbf{Z n}$} & \multicolumn{3}{|l|}{$\mathbf{C u}$} & \multirow{2}{*}{$\frac{\mathrm{Pb}}{25^{\circ} \mathrm{C}}$} & \multirow{2}{*}{$\frac{\mathrm{Zn}}{25^{\circ} \mathrm{C}}$} & \multirow{2}{*}{$\frac{\mathrm{Cu}}{25^{\circ} \mathrm{C}}$} & \multirow{2}{*}{$\begin{array}{l}\mathrm{Pb} \\
25^{\circ} \mathrm{C}\end{array}$} & \multirow{2}{*}{$\frac{\mathrm{Zn}}{25^{\circ} \mathrm{C}}$} & \multirow{2}{*}{$\frac{\mathrm{Cu}}{25^{\circ} \mathrm{C}}$} \\
\hline & & & $15^{\circ} \mathrm{C}$ & $25^{\circ} \mathrm{C}$ & $45^{\circ} \mathrm{C}$ & $15^{\circ} \mathrm{C}$ & $25^{\circ} \mathrm{C}$ & $45^{\circ} \mathrm{C}$ & $15^{\circ} \mathrm{C}$ & $25^{\circ} \mathrm{C}$ & $45^{\circ} \mathrm{C}$ & & & & & & \\
\hline \multirow{9}{*}{ 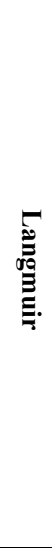 } & \multirow{4}{*}{ 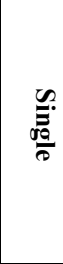 } & $Q_{m, \text { mass }}$ & 125.79 & 140.27 & 237.03 & 72.65 & 77.81 & 83.88 & 10.32 & 9.01 & 9.27 & 65.27 & 67.51 & 40.50 & 68.13 & 46.83 & 15.63 \\
\hline & & $Q_{m, m o l}$ & 0.607 & 0.677 & 1.145 & 1.117 & 1.197 & 1.29 & 0.160 & 0.141 & 0.145 & 0.315 & 1.039 & 0.633 & 0.329 & 0.720 & 0.244 \\
\hline & & $K_{L}$ & 0.0061 & 0.0046 & 0.0022 & 0.0058 & 0.0068 & 0.0078 & 0.0044 & 0.0073 & 0.013 & 0.0017 & 0.0045 & 0.0019 & 0.020 & 0.0029 & $\begin{array}{c}0.001 \\
0\end{array}$ \\
\hline & & $\mathbf{R}^{2}$ & 0.996 & 0.997 & 0.991 & 0.996 & 0.995 & 0.994 & 0.997 & 0.995 & 0.991 & 0.991 & 0.995 & 0.998 & 0.980 & 0.994 & 0.997 \\
\hline & \multirow{4}{*}{ 交 } & $Q_{m, \text { mass }}$ & - & 65.52 & - & - & 40.38 & - & - & 0 & - & 122.06 & 125.18 & 124.79 & 45.38 & 45.12 & 0 \\
\hline & & $Q_{m, m o l}$ & - & 0.312 & - & - & 0.621 & - & - & 0 & - & 0.0583 & 1.926 & 1.950 & 0.219 & 0.694 & 0 \\
\hline & & $K_{L}$ & - & 0.01746 & - & - & 0.00046 & - & - & - & - & 0.014 & 0.019 & 0.015 & 0.0039 & 0.0022 & - \\
\hline & & $\mathbf{R}^{2}$ & - & 0.994 & - & - & 0.988 & - & - & - & - & 0.978 & 0.993 & 0.991 & 0.998 & 0.999 & - \\
\hline & & $P$ & & 0.467 & & & 0.519 & & & $\mathbf{0}$ & & 0.184 & 1.854 & 3.081 & 0.666 & 0.963 & $\mathbf{0}$ \\
\hline \multirow{6}{*}{ 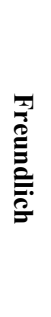 } & \multirow{3}{*}{ 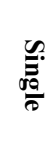 } & $\boldsymbol{K}_{F}$ & 6.91 & 5.00 & 2.23 & 2.28 & 2.85 & 3.52 & 0.27 & 0.47 & 0.98 & 0.98 & 2.10 & 0.504 & 16.66 & 0.58 & 0.10 \\
\hline & & $1 / n$ & 0.42 & 0.48 & 0.65 & 0.52 & 0.50 & 0.49 & 0.52 & 0.44 & 0.34 & 0.65 & 0.57 & 0.71 & 0.21 & 0.62 & 0.80 \\
\hline & & $\mathbf{R}^{2}$ & 0.998 & 0.998 & 0.963 & 0.989 & 0.982 & 0.986 & 0.988 & 0.981 & 0.922 & 0.968 & 0.966 & 0.989 & 0.744 & 0.971 & 0.790 \\
\hline & \multirow{3}{*}{ 家 } & $\boldsymbol{K}_{F}$ & - & 6.45 & - & - & 0.148 & - & - & - & - & 12.37 & 17.23 & 13.63 & 1.15 & 0.30 & - \\
\hline & & $1 / n$ & - & 0.39 & - & - & 0.94 & - & - & - & - & 0.38 & 0.32 & 0.35 & 0.64 & 0.72 & - \\
\hline & & $\mathbf{R}^{2}$ & - & 0.941 & - & - & 0.979 & - & - & - & - & 0.994 & 0.891 & 0.917 & 0.995 & 0.997 & - \\
\hline
\end{tabular}

Langmuir model: $Q_{e}=\frac{Q_{m} K_{L} C_{e}}{1+K_{L} C_{e}}, \mathrm{P}=\frac{Q_{\text {max }, \text { single }}}{Q_{\text {max } \text { multiple }}}$.

$Q_{e}(\mathrm{mg} / \mathrm{g})$ is the adsorption capacity; $Q_{m \text {,mass }}(\mathrm{mg} / \mathrm{g}) / Q_{m, \text { mol }}(\mathrm{mmol} / \mathrm{g})$ represents the maximum adsorption capacity; $K_{L}(\mathrm{~L} / \mathrm{mg})$ is an Langmuir constant relate to the affinity between adsorbents and adsorbate; $\mathrm{P}$ factor is a dimensionless parameter to estimate the selectivity for heavy metals.

Freundlich model: $Q_{e}=K_{F} C_{e}^{1 / n}$.

$K_{F}\left(\mathrm{mg}^{1-\mathrm{n} .} \cdot \mathrm{L}^{\mathrm{n}} / \mathrm{g}\right)$ is a constant related to the adsorption capacity of adsorbent when the equilibrium metal ions concentration equals to 1 ; $\mathrm{n}$ states the degree of dependence of the adsorption on the equilibrium concentration. 
The multiple ion solution was applied to further investigate the selective adsorption property of $\mathrm{PPy} / \mathrm{TiO}_{2}$ composite, which is important in adsorption engineering but is rarely reported. The Langmuir model still describes the adsorption data best, indicating that the multi-adsorption is still monolayer. It is reasonable that the adsorption capacities $\left(Q_{m}\right)$ deteriorate to some extent due to the competition between heavy metals for the adsorption sites. To better correlate the data obtained from single metal equilibrium with the multi-metal data, the $\boldsymbol{P}$ factor, which is a dimensionless parameter shown in Eq. (3), is introduced.

$\boldsymbol{P}=\frac{Q_{\max , \text { single }}}{Q_{\max , \text { multiple }}}$

Where, $Q_{\text {max,single }}$ and $Q_{\text {max }}$ multiple are the maximum adsorption capacity of heavy metals in single and multi-component systems. Obviously, the higher the affinity towards one metal, the higher the value of $\boldsymbol{P}$ is; and the better the selectivity the composite has, the bigger the difference in the $\boldsymbol{P}$ values is for different metal ions. The $\boldsymbol{P}$ values of the composite for three heavy metals are also recorded in Table 2. It is interesting to see that the $\boldsymbol{P}$ values show a descending order of $\mathrm{Zn}^{2+}>\mathrm{Pb}^{2+}>>\mathrm{Cu}^{2+}$, and the adsorption of $\mathrm{Cu}^{2+}$ is almost completely forbidden in the multi-component system, suggesting that the $\mathrm{PPy} / \mathrm{TiO}_{2}$ composite can be applied to separate and recycle heavy metals from $\mathrm{Cu}^{2+}$ rich electroplating effluent without the influence and competition of $\mathrm{Cu}^{2+}$. It should be noted that there is not a mechanism about selective adsorption that can perfectly explain all the experimental results yet, and the reported results contradict with each other in reported literature. For example, Z.J. Xu et al. ${ }^{36}$ reported the selective adsorption of heavy metals to be in the order of $\mathrm{Cu}(\mathrm{II})>\mathrm{Co}(\mathrm{II})>\mathrm{Ni}(\mathrm{II})$ for a $\mathrm{SG}-\mathrm{H}_{2} \mathrm{~L}^{2}$ composite, and they suggested that it may be caused by other factors involved in the adsorption process, such as the cationic radius, hydration energy and acidity/basicity of the interactive species. However, contradicting results were observed by J. Ali et al. ${ }^{37}$ who suggested the selective adsorption order of a 


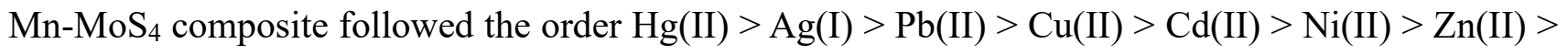
$\mathrm{Co}(\mathrm{II})$, in which the mechanism of selectivity is based on the Hard-Soft-Acid-Base theory. In addition, $\operatorname{Ag}(\mathrm{I})$, which carries only one positive charge, outperforms other ions which have greater charges, challenging the theory that the more charged ions would have higher adsorption priority. Another differing result was reported of a $\mathrm{PPy} / \mathrm{TiO}_{2}$ composite that had selective adsorption in the order $\mathrm{Zn}^{2+}>\mathrm{Pb}^{2+}>>\mathrm{Cu}^{2+}$, even though $\mathrm{Zn}^{2+}$ has a smaller ionic radii and Pauling electronegativity $(0.74 \mathrm{~nm}$ and 1.65, respectively) than $\mathrm{Pb}^{2+}(0.97 \mathrm{~nm}$ and 2.33 , respectively $)$ and $\mathrm{Cu}^{2+}(0.7 \mathrm{~nm}$ and 1.9 , respectively), suggesting that the selectivity of the adsorbent majorly depends on both of the adsorbent and adsorbate, and the mechanism proposed before cannot well explain all these situations.

In order to know more about the selectivity of the $\mathrm{PPy} / \mathrm{TiO}_{2}$ composite, competitive adsorption studies of PPy and $\mathrm{TiO}_{2}$ was also conducted, which were summarized in Fig. $\mathbf{S 5}$ (d-i) and Table 2. It is interesting to notice that that $\mathrm{TiO}_{2}$ showed a similar adsorption behavior in a multi-component system to the $\mathrm{PPy} / \mathrm{TiO}_{2}$ composite. Such behavior was not observed for PPy. In addition, $\mathrm{TiO}_{2}$ did show a similar selectivity order to that of $\mathrm{PPy} / \mathrm{TiO}_{2}$, which follows $\mathrm{Zn}^{2+}>\mathrm{Pb}^{2+}>\mathrm{Cu}^{2+}$. Therefore, it can be deduced that the selectivity for heavy metals for this composite was determined by $\mathrm{TiO}_{2}$ instead of PPy. It can be hypothesized that $\mathrm{Pb}^{2+}$ and $\mathrm{Zn}^{2+}$ are favored by $\mathrm{TiO}_{2}$, while $\mathrm{Cu}^{2+}$ is not favored by $\mathrm{TiO}_{2}$ and the $\mathrm{PPy} / \mathrm{TiO}_{2}$ composite, even though PPy has a good affinity towards $\mathrm{Cu}^{2+} \cdot \mathrm{Cu}^{2+}$ can be only adsorbed by the PPy by the limited imine groups. Despite the prior information, the reason why a metal oxide would have special affinity towards specific heavy metal ions could not be given. However, inspired by the work conducted by O.A. Oyetade et al. ${ }^{38}$, who conducted DFT calculations to simulate the combination of ions with acid functionalized multiwalled carbon nanotubes on a lattice structure 
scale, we hypothesize herein that the selectivity of the metal oxide to heavy metal ions should relate to the compatibility for the lattice structures of metal oxides and heavy metal ion hydroxide. The further investigation in this area will be in the subject of our future work.

From the fitting results of the Dubinin-Radushkevich and the Temkin model, it can be seen in Fig. S6$\boldsymbol{S 7}$ and Table $\boldsymbol{S 3}$ that the adsorption free energy $(\boldsymbol{E})$ and heat $(\boldsymbol{B})$ also follow the increasing trend with the temperature, which is consistent with the results from the Langmuir model. However, these two models cannot describe the data well, therefore the value of the adsorption free energy $(\boldsymbol{E})$ and heat (B) are not used to determine the adsorption mechanism.

\subsection{Synergistic adsorption and selective adsorption mechanism}

Inspired by the interesting selective adsorption properties of the $\mathrm{PPy} / \mathrm{TiO}_{2}$ composite, we continued to design and carry out experiments to investigate the mechanism of the synergistic adsorption between PPy and $\mathrm{TiO}_{2}$, and the selective adsorption mechanism for heavy metals.

\subsubsection{Adsorption sites}

FT-IR analysis before and after heavy metal adsorption for $\mathrm{TiO}_{2}, \mathrm{PPy}$ and the $\mathrm{PPy} / \mathrm{TiO}_{2}$ composite were performed (Fig.S1(b-d)) to determine the adsorption sites, and the main characteristic peaks were listed in Table $\boldsymbol{S} 1$. For $\mathrm{TiO}_{2}$, the peaks assigned to the hydroxyls at $3419 \mathrm{~cm}^{-1}$ and $1629 \mathrm{~cm}^{-1}$ showed an obvious red shift to higher wavenumbers after adsorbing $\mathrm{Pb}^{2+}, \mathrm{Zn}^{2+}$ and $\mathrm{Cu}^{2+}$, suggesting an interaction between the hydroxyls on the surface of $\mathrm{TiO}_{2}$ and heavy metals after dedoping ${ }^{39}$. The peak shift of $\mathrm{Cu}^{2+}$ was relatively smaller than the other two ions, confirming the result obtained by the competitive isotherm investigation that adsorption of $\mathrm{Cu}^{2+}$ is not favorable for $\mathrm{TiO}_{2}$. As for PPy and 
the $\mathrm{PPy} / \mathrm{TiO}_{2}$ composite, a red shift was clearly observed for the peak ascribed to $\mathrm{C}-\mathrm{N}$ situated at around $1442 \mathrm{~cm}^{-1}$ as well, and its intensity became very weak after adsorption, indicating a new environment around the pyrrolylium nitrogen on the PPy chain ${ }^{24}$. This result may be one of the important evidences for the ionic exchange and dedoping of $\mathrm{TiO}_{2}\left(\mathrm{O}^{-}\right)$during adsorption.

\subsubsection{Synergistic adsorption and selective adsorption mechanism}

It is difficult to interpret the selective adsorption order of $\mathrm{Zn}^{2+}>\mathrm{Pb}^{2+}>>\mathrm{Cu}^{2+}$ for the $\mathrm{PPy} / \mathrm{TiO}_{2}$ composite if using the Hard-Soft-Acid-Base theory or the properties of heavy metals only. Therefore, the synergistic adsorption between $\mathrm{TiO}_{2}$ and $\mathrm{PPy}$ in the selective adsorption process was also considered. As we discussed above, the $\mathrm{TiO}_{2}\left(\mathrm{O}^{-}\right)$together with $\mathrm{SO}_{4}{ }^{2-}$ acts as a dopant and is involved in the charge-transfer interaction with $\mathrm{PPy}$ in the $\mathrm{PPy} / \mathrm{TiO}_{2}$ composite. However, the unstable oxidization doped state of PPy is relatively easy to dedope or to exchange dopants with rich ions such as $\mathrm{NO}_{3}{ }^{-}$in the heavy metal ion solution at $\mathrm{pH}>3{ }^{40}$, and some imine could be formed. To illuminate this process, XPS investigations on the composite after adsorption was conducted. The N1s spectra of $\mathrm{PPy} / \mathrm{TiO}_{2}$ after adsorption are depicted in Fig.1, and the assignments and their ratio of peak area are presented in Table 3 to illustrate the change of $\mathrm{N}$ nature. It shows an interesting result: a decreased ratio of $-\mathrm{N}^{+}-$, an increased ratio of $=\mathrm{N}-$, and an unchanged ratio of $-\mathrm{NH}-$; confirming a certain degree of dedoping for the composite. However, the TGA results shown in Table $\mathbf{1}$ infer that the mass of doping ions $\left(300-600{ }^{\circ} \mathrm{C}\right)$ still increased after adsorption, suggesting that the dedoped ions should be the $\mathrm{TiO}_{2}\left(\mathrm{O}^{-}\right)$instead of $\mathrm{SO}_{4}{ }^{2-}$; some $\mathrm{TiO}_{2}\left(\mathrm{O}^{-}\right)$may be also exchanged by $\mathrm{NO}_{3}{ }^{-}$doping into PPy chain ${ }^{24}$. It is reasonable because the $\mathrm{SO}_{4}{ }^{2-}$ has a large size and is relatively hard to dedope from the PPy chain. From the XPS result, another interesting result can be also noticed is that for $\mathrm{Pb}^{2+}$ and $\mathrm{Zn}^{2+}$, which are 
favorable by $\mathrm{PPy} / \mathrm{TiO}_{2}$, the dedoping rate is much lower (larger $\mathrm{A}\left(-\mathrm{N}^{+}-\right) / \mathrm{A}(=\mathrm{N}-)$ ) than for $\mathrm{Cu}^{2+}$, which is unfavorable. It can be inferred from this result that $\mathrm{Cu}^{2+}$ may be mostly adsorbed on PPy, in a different manner than $\mathrm{Pb}^{2+}$ and $\mathrm{Zn}^{2+}$. This is due to the chemical equilibrium between the metal ion and PPy, where the dedoping process can be promoted by heavy metal ions if heavy metal ions have an interaction with PPy as follows:

$\operatorname{PPy}\left(-\mathrm{N}^{+}-\right) \mathrm{X}^{-}==\operatorname{PPy}(=\mathrm{N}-)+\mathrm{HX}$

$\operatorname{PPy}(=\mathrm{N}-)+\mathrm{Cu}^{2+}==\operatorname{PPy}(=\mathrm{N}-) \mathrm{Cu}^{2+}$.

This reaction can be also confirmed by the XPS spectra of $\mathrm{Cu} 2 \mathrm{p}$, in which the $\mathrm{Cu}-\mathrm{N}$ can be obviously detected after adsorption (Fig. 1(b)), suggesting the main adsorption site for $\mathrm{Cu}^{2+}$ is on the PPy through the imine. The similar shape line is also found in $\mathrm{Cu} / \mathrm{N}$ doped $\mathrm{TiO}_{2}{ }^{41}$. As for $\mathrm{Pb}^{2+}$ and $\mathrm{Zn}^{2+}$, the peaks for $\mathrm{Pb}-\mathrm{N}$ and $\mathrm{Zn}-\mathrm{N}$ are overlapped and only hydrated $(\mathrm{Pb}-\mathrm{O}$ and $\mathrm{Zn}-\mathrm{O})$ and nitrated forms can be detected ${ }^{42,43}$, confirming that $\mathrm{Zn}^{2+}$ and $\mathrm{Pb}^{2+}$ were mainly adsorbed on $\mathrm{TiO}_{2}$ while $\mathrm{Cu}^{2+}$ was adsorbed by PPy on the imine group, which further supports the hypothesis that $\mathrm{Zn}^{2+}$ and $\mathrm{Pb}^{2+}$ are more favorable by $\mathrm{TiO}_{2}$. From the XPS result, it can also be seen that the oxidation rate of PPy after adsorption decreases to around $20 \%$, which is attributed by the hydrolysis in the non-acid aqueous solution. 
Table 3 The assignment and ratio of peak areas in the XPS N 1s core level spectra of the $\mathrm{PPy} / \mathrm{TiO}_{2}$ composite after $\mathrm{Pb}^{2+}, \mathrm{Zn}^{2+}$ and $\mathrm{Cu}^{2+}$ adsorption (the FWHM is set as $1.4 \mathrm{eV}$, and the \%Lorentzian-Gaussian is set as $20 \%$ ).

\begin{tabular}{|c|c|c|c|c|c|c|c|c|c|}
\hline & $\mathrm{Pb}$ & & & $\mathrm{Zn}$ & & & $\mathrm{Cu}$ & & \\
\hline Assignment ${ }^{16}$ & $\begin{array}{l}\text { Binding } \\
\text { energy/eV }\end{array}$ & $\begin{array}{l}\text { Ratio of peak } \\
\text { area }\end{array}$ & $\mathrm{A}\left(-\mathrm{N}^{+}-\right) / \mathrm{A}(=\mathrm{N}-)$ & $\begin{array}{l}\text { Binding } \\
\text { energy/eV }\end{array}$ & $\begin{array}{l}\text { Ratio of peak } \\
\text { area }\end{array}$ & $\mathrm{A}\left(-\mathrm{N}^{+}-\right) / \mathrm{A}(=\mathrm{N}-)$ & $\begin{array}{l}\text { Binding } \\
\text { energy/eV }\end{array}$ & $\begin{array}{l}\text { Ratio of peak } \\
\text { area }\end{array}$ & $\mathrm{A}\left(-\mathrm{N}^{+}-\right) / \mathrm{A}(=\mathrm{N}-)$ \\
\hline$=\mathrm{N}-$ & 397.87 & $4.869 \%$ & \multirow{4}{*}{2.264} & 397.97 & $4.176 \%$ & \multirow{4}{*}{3.971} & 398.17 & $7.668 \%$ & \multirow{4}{*}{0.771} \\
\hline$-\mathrm{NH}-$ & 399.77 & $79.269 \%$ & & 399.77 & $78.168 \%$ & & 399.77 & $76.534 \%$ & \\
\hline$-\mathrm{N}^{+}-$ & 400.97 & $11.001 \%$ & & 401.07 & $14.104 \%$ & & 401.27 & $5.856 \%$ & \\
\hline $\mathrm{NO}_{3}^{-}$ & 402.07 & $4.861 \%$ & & 402.27 & $3.552 \%$ & & 402.17 & $9.942 \%$ & \\
\hline
\end{tabular}


Taking the above into consideration, we summarize and propose the mechanism on the synergistic adsorption for $\mathrm{PPy} / \mathrm{TiO}_{2}$ composite for the first time as follows: $\mathrm{TiO}_{2}\left(\mathrm{O}^{-}\right)$together with $\mathrm{SO}_{4}{ }^{2-}$ is suggested as the dopants for the PPy and is involved in charge-transfer interactions with PPy in the $\mathrm{PPy} / \mathrm{TiO}_{2}$ system. After the composite is dosed with the heavy metal solution at $\mathrm{pH}$ greater than 3 , the exchange/dedoping process of dopants can occur. A part of $\mathrm{TiO}_{2}\left(\mathrm{O}^{-}\right)$would be dedoped and exchanged by the counter-anions in the solution (here is $\mathrm{NO}_{3}{ }^{-}$) due to the high concentration of rich $\mathrm{NO}_{3}{ }^{-}$in the solution ${ }^{44}$. After being dedoped, the negatively charged $\mathrm{TiO}_{2}\left(\mathrm{O}^{-}\right)$needs to be electrically neutralized. In solutions at $\mathrm{pH}=5$, heavy metal ions would be preferentially attracted to $\mathrm{TiO}_{2}\left(\mathrm{O}^{-}\right)$for electroneutrality. Thus, the selective adsorption is mainly achieved at the $\mathrm{TiO}_{2}$, resulting in the interesting phenomenon that the selectivity of the composite is determined by the interaction between $\mathrm{TiO}_{2}$ and heavy metal ions instead of PPy. Therefore, the $\mathrm{PPy} / \mathrm{TiO}_{2}$ composite has better affinity to $\mathrm{Zn}^{2+}$ and $\mathrm{Pb}^{2+}$ than $\mathrm{Cu}^{2+}$, just as $\mathrm{TiO}_{2}$ does. In other words, the novel selectivity is achieved through the synergistic adsorption between $\mathrm{PPy}$ and $\mathrm{TiO}_{2}$. For the adsorption mechanism, according to R. ZareDorabei and our previous work, hydroxyls become negatively charged after dedoping from PPy, resulting in the adsorption of heavy metal ions with positive charge through the electrostatic attraction. Therefore, the electrostatic attraction would be an important mechanism for the adsorption. In addition, for the pyrrolylium nitrogen which has lone pair electron in the PPy, the chelation of nitrogen to the heavy metal ions with unoccupied orbital could be another important mechanism for the adsorption after dedoping. The adsorption mechanism could be expressed as follows:

2 Composite- $\mathrm{O}^{-}$(hydroxyl) $+\mathrm{M}^{2+}$ (heavy metal ion) $\rightarrow$ 2Composite- $\mathrm{O}^{---} \mathrm{M}^{2+}$ (electrostatic attraction)

Composite-N: (pyrrolylium nitrogen) $+\mathrm{M}^{2+}$ (heavy metal ion) $\rightarrow$ Composite- $\mathrm{N}: \rightarrow \mathrm{M}^{2+}$ (chelation) 
It should be noted that even though the PPy has adsorption capacity to heavy metals through chelation, however, the loading of PPy is low compared to $\mathrm{TiO}_{2}$ from TGA result. Therefore, the selective adsorption property is still determined by $\mathrm{TiO}_{2}$.

We conducted the experiments by adjusting the solution pH (depicted in Fig. S8) to confirm this synergistic mechanism. The adsorption capacities for $\mathrm{Pb}^{2+}, \mathrm{Zn}^{2+}$ and $\mathrm{Cu}^{2+}$ increased with the increased $\mathrm{pH}$. This result supports the synergistic mechanism we proposed because when the composite is dosed into the solution with higher $\mathrm{pH}$, the dedoping of the dopant and the dopant exchange would be greatly improved due to the low concentration of $\mathrm{H}^{+}$, resulting in the available of the $\mathrm{TiO}_{2}\left(\mathrm{O}^{-}\right)$adsorption site and enhancement of the adsorption capacity for heavy metal ions ${ }^{24}$. In addition, the amount of imine group could be also increased at high $\mathrm{pH}$, which may also increase the adsorption capacity ${ }^{27}$.

\section{Conclusion}

The investigation on the mechanism of the synergistic adsorption between polymer and metal oxide is an important issue for the adsorbent design and application. Herein, the mechanism on the synergistic adsorption between polymer and metal oxide in a polymer/metal oxide composite was discovered and proposed for the first time, and the self-doping nature of metal oxide on polymer was carefully illuminated. The PPy in its oxidized p-type doping state with $31.2 \%$ doping degree is coated on the surface of the $\mathrm{TiO}_{2}$ which is in the n-type state, forming an interesting charge-transfer structure. This interaction results in the interesting selective adsorption property that $\mathrm{Zn}^{2+}$ can be selectively adsorbed with $77.81 \mathrm{mg} / \mathrm{g}$ adsorption capacity while the adsorption for $\mathrm{Cu}^{2+}$ was totally suppressed in a multiple 
heavy metal ion solution. The XPS, TGA and FTIR were applied for the mechanism investigation. The results show peak shifts assigned to hydroxyls and pyrrolylium nitrogen in FTIR, a decreased ratio of $-\mathrm{N}^{+}-$, an increased ratio of $=\mathrm{N}-$, and an unchanged ratio of $-\mathrm{NH}-$ in $\mathrm{XPS}$, and weight loss ascribed to doping ions in TGA, confirming a certain degree of dedoping for the composite, and the exchange/dedoping of $\mathrm{TiO}_{2}\left(\mathrm{O}^{-}\right)$occurred during the adsorption process. It further results in the interesting phenomenon that the selectivity of the composite was determined by the $\mathrm{TiO}_{2}$. This mechanism we proposed herein satisfactorily explains the interesting properties of synergistic adsorption and selective adsorption in this system. It may also be suitable in other polymer/metal oxide composites whose polymer can conduct the doping-dedoping process, such as polythiophene and polyaniline, and gives a guideline to get insight into the mechanism on the selective adsorption in other adsorbents. With this guideline, the heavy metal ions can be recycled with higher efficiency and lower cost compared to other treatment method. However, the $\mathrm{Pb}^{2+}$ and $\mathrm{Zn}^{2+}$ cannot be separated by $\mathrm{PPy} / \mathrm{TiO}_{2}$. Meanwhile, the reason why the $\mathrm{TiO}_{2}$ has special adsorption affinity to $\mathrm{Zn}^{2+}$ and poor affinity to $\mathrm{Cu}^{2+}$ remains unknown. We hypothesize herein that the selectivity of the metal oxide to heavy metal ions should relate to the compatibility for the lattice structures of metal oxides and heavy metal ion hydroxide. The further investigation will be conducted in our future work in this case.

\section{ASSOCIATED CONTENT}

\section{Supporting information}

Additional figures: FTIR spectra of $\mathrm{PPy}, \mathrm{TiO}_{2}$ and the $\mathrm{PPy} / \mathrm{TiO}_{2}$ composite before and after $\mathrm{Pb}^{2+}, \mathrm{Zn}^{2+}$ and $\mathrm{Cu}^{2+}$ adsorption; TGA analysis of $\mathrm{PPy}, \mathrm{TiO}_{2}$ and the $\mathrm{PPy} / \mathrm{TiO}_{2}$ composite before and after adsorption of $\mathrm{Pb}^{2+}, \mathrm{Zn}^{2+}$ and $\mathrm{Cu}^{2+} ; \mathrm{XRD}$ spectra of $\mathrm{PPy}, \mathrm{TiO}_{2}$ and the $\mathrm{PPy} / \mathrm{TiO}_{2}$ composite; $\mathrm{SEM}$ and 
TEM images of the $\mathrm{PPy} / \mathrm{TiO}_{2}$ composite; Single and multi-component adsorption isotherms for the adsorption of heavy metals onto the PPy/ $\mathrm{TiO}_{2}$ composite, PPy and $\mathrm{TiO}_{2}$, fitting with Langmuir model, Freundlich model, linear form of Dubinin-Radushkevich model and Temkin model; The adsorption capacities of the $\mathrm{PPy} / \mathrm{TiO}_{2}$ composite for $\mathrm{Pb}^{2+}, \mathrm{Zn}^{2+}$ and $\mathrm{Cu}^{2+}$ in different initial $\mathrm{pH}$.

Additional table: Assignments of the FT-IR absorptions for $\mathrm{PPy}, \mathrm{TiO}_{2}$ and the $\mathrm{PPy} / \mathrm{TiO}_{2}$ composite before and after adsorption of $\mathrm{Pb}^{2+}, \mathrm{Zn}^{2+}$ and $\mathrm{Cu}^{2+}$; The textural properties of $\mathrm{PPy}, \mathrm{TiO}_{2}$ and the $\mathrm{PPy} / \mathrm{TiO}_{2}$ composite before and after adsorption; Single and multi-component adsorption isotherms parameters describing the adsorption of heavy metals $\left(\mathrm{Pb}^{2+}, \mathrm{Zn}^{2+}, \mathrm{Cu}^{2+}\right)$ onto the $\mathrm{PPy} / \mathrm{TiO}_{2}$ composite, based on Dubinin-Radushkevich and Temkin models.

Additional scheme: Interconversions between the various redox states in PPy.

Additional experiments and discussion: Calculation for the amount of $\mathrm{SO}_{4}{ }^{2-}$ in the PPy chain; Kinetic investigation; Regeneration; Field sample analysis.

\section{Acknowledgement}

The authors gratefully acknowledge Esther Townsend for her kind help with the language and her helpful suggestions to improve the quality of our paper. The authors gratefully acknowledge the Shaanxi Key research and development projects, China (Grant No. 2017SF-386) and the financial supports from the National Natural Science Foundation of China (Grant No.21307098). 


\section{References}

1. Isaac, R. A.; Gil, L.; Cooperman, A. N.; Hulme, K.; Eddy, B.; Ruiz, M.; Jacobson, K.; Larson, C.; Pancorbo, O. C., Corrosion in Drinking Water Distribution Systems: A Major Contributor of Copper and Lead to Wastewaters and Effluents. Environmental science \& technology 1997, 31, (11), 3198-3203.

2. Voegelin, A.; Vulava, V. M.; Kretzschmar, R., Reaction-Based Model Describing Competitive Sorption and Transport of $\mathrm{Cd}, \mathrm{Zn}$, and $\mathrm{Ni}$ in an Acidic Soil. Environmental science \& technology 2001, 35, (8), 1651-1657.

3. Celis, R.; Hermosín, M. C.; Cornejo, J., Heavy Metal Adsorption by Functionalized Clays. Environmental science \& technology 2000, 34, (21), 4593-4599.

4. Xu, Y.; Axe, L.; Yee, N.; Dyer, J. A., Bidentate Complexation Modeling of Heavy Metal Adsorption and Competition on Goethite. Environmental science \& technology 2006, 40, (7), 2213-2218.

5. Liu, X.; Liu, M.; Zhang, L., Co-adsorption and sequential adsorption of the co-existence four heavy metal ions and three fluoroquinolones on the functionalized ferromagnetic $3 \mathrm{D} \mathrm{NiFe}{ }_{2} \mathrm{O}_{4}$ porous hollow microsphere. Journal of colloid and interface science 2018, 511, (Supplement C), 135-144.

6. Kang, E. T.; Neoh, K. G.; Tan, K. L., Polyaniline: A polymer with many interesting intrinsic redox states. Progress in Polymer Science 1998, 23, (2), 277-324.

7. Huang, J.; Zheng, Y.; Luo, L.; Feng, Y.; Zhang, C.; Wang, X.; Liu, X., Facile preparation of highly hydrophilic, recyclable high-performance polyimide adsorbents for the removal of heavy metal ions. Journal of hazardous materials 2016, 306, 210-219.

8. Li, Z.-J.; Huang, Z.-W.; Guo, W.-L.; Wang, L.; Zheng, L.-R.; Chai, Z.-F.; Shi, W.-Q., Enhanced Photocatalytic Removal of Uranium(VI) from Aqueous Solution by Magnetic TiO2/Fe3O4 and Its Graphene Composite. Environmental science \& technology 2017, 51, (10), 5666-5674.

9. Li, M.; Noriega-Trevino, M. E.; Nino-Martinez, N.; Marambio-Jones, C.; Wang, J.; Damoiseaux, R.; Ruiz, F.; Hoek, E. M. V., Synergistic Bactericidal Activity of Ag-TiO2 Nanoparticles in Both Light and Dark Conditions. Environmental science \& technology 2011, 45, (20), 8989-8995.

10. Fukahori, S.; Ichiura, H.; Kitaoka, T.; Tanaka, H., Photocatalytic Decomposition of Bisphenol A in Water Using Composite $\mathrm{TiO}^{2}$-Zeolite Sheets Prepared by a Papermaking Technique. Environmental science \& technology 2003, 37, (5), 1048-1051.

11. Yang, J.; Wu, J.-X.; Lü, Q.-F.; Lin, T.-T., Facile Preparation of Lignosulfonate-Graphene OxidePolyaniline Ternary Nanocomposite as an Effective Adsorbent for $\mathrm{Pb}(\mathrm{II})$ Ions. ACS Sustainable Chemistry \& Engineering 2014, 2, (5), 1203-1211.

12. Muhammad Ekramul Mahmud, H. N.; Huq, A. K. O.; Yahya, R. b., The removal of heavy metal ions from wastewater/aqueous solution using polypyrrole-based adsorbents: a review. RSC Advances 2016, 6, (18), 14778-14791.

13. Chen, J.; Feng, J.; Yan, W., Influence of metal oxides on the adsorption characteristics of PPy/metal oxides for Methylene Blue. Journal of colloid and interface science 2016, 475, 26-35.

14. Chen, J.; Shu, C.; Wang, N.; Feng, J.; Ma, H.; Yan, W., Adsorbent synthesis of polypyrrole/ $/ \mathrm{TiO}_{2}$ for effective fluoride removal from aqueous solution for drinking water purification: Adsorbent characterization and adsorption mechanism. Journal of colloid and interface science 2017, 495, 44-52.

15. Bonifas, A. P.; McCreery, R. L., Solid State Spectroelectrochemistry of Redox Reactions in Polypyrrole/Oxide Molecular Heterojunctions. Analytical Chemistry 2012, 84, (5), 2459-2465.

16. Tan, K. L.; Tan, B. T. G.; Kang, E. T.; Neoh, K. G., Chemical nature of the nitrogens in polypyrrole and nitrogen-substituted polypyrrole: a comparative study by X-ray photoelectron spectroscopy. Journal of Materials Science 1992, 27, (15), 4056-4060. 
17. Bradl, H. B., Adsorption of heavy metal ions on soils and soils constituents. Journal of colloid and interface science 2004, 277, (1), 1-18.

18. Lim, C. W.; Song, K.; Kim, S. H., Synthesis of PPy/silica nanocomposites with cratered surfaces and their application in heavy metal extraction. Journal of Industrial and Engineering Chemistry 2012, $18,(1), 24-28$.

19. Mahmud, H.; Hosseini, S.; Yahya, R. B., Removal of Nickel Ions from Aqueous Solution by Polypyrrole Conducting Polymer. In Advanced Materials Engineering and Technology Ii, Abdullah, M. M. A.; Jamaludin, L.; Abdullah, A.; AbdRazak, R.; Hussin, K., Eds. Trans Tech Publications Ltd: StafaZurich, 2014; Vol. 594-595, 793-797.

20. Hosseini, S.; Ekramul Mahmud, N. H. M.; Binti Yahya, R.; Ibrahim, F.; Djordjevic, I., Polypyrrole conducting polymer and its application in removal of copper ions from aqueous solution. Materials Letters 2015, 149, 77-80.

21. Lin, Y.; Cui, X.; Bontha, J., Electrically Controlled Anion Exchange Based on Polypyrrole and Carbon Nanotubes Nanocomposite for Perchlorate Removal. Environmental science \& technology 2006, 40, (12), 4004-4009.

22. Li, J.; Feng, J.; Yan, W., Excellent adsorption and desorption characteristics of polypyrrole/ $/ \mathrm{TiO}_{2}$ composite for Methylene Blue. Appl. Surf. Sci. 2013, 279, 400-408.

23. Ullah, H., Inter-molecular interaction in Polypyrrole/TiO 2 : A DFT study. Journal of Alloys and Compounds 2017, 692, 140-148.

24. Tan, K. L.; Tan, B. T. G.; Kang, E. T.; Neoh, K. G., The chemical nature of the nitrogens in polypyrrole and polyaniline - a comparative-study by X-ray photoelectron-spectroscopy. J. Chem. Phys. 1991, 94, (8), 5382-5388.

25. Xu, J.; Yao, P.; Li, X.; He, F., Synthesis and characterization of water-soluble and conducting sulfonated polyaniline/para-phenylenediamine-functionalized multi-walled carbon nanotubes nanocomposite. Materials Science and Engineering B-Advanced Functional Solid-State Materials 2008, 151, (3), 210-219.

26. Yu, J. C.; Yu, J. G.; Ho, W. K.; Jiang, Z. T.; Zhang, L. Z., Effects of F- doping on the photocatalytic activity and microstructures of nanocrystalline $\mathrm{TiO}_{2}$ powders. Chemistry of Materials 2002, 14, (9), 3808-3816.

27. Chen, J.; Wang, N.; Ma, H.; Zhu, J.; Feng, J.; Yan, W., Facile Modification of a Polythiophene/TiO Composite Using Surfactants in an Aqueous Medium for an Enhanced $\mathrm{Pb}$ (II) Adsorption and Mechanism Investigation. Journal of Chemical \& Engineering Data 2017, 62, (7), 2208-2221.

28. Kruk, M.; Jaroniec, M., Gas adsorption characterization of ordered organic-inorganic nanocomposite materials. Chem. Mater. 2001, 13, (10), 3169-3183.

29. An, H. K.; Park, B. Y.; Kim, D. S., Crab shell for the removal of heavy metals from aqueous solution. Water Res. 2001, 35, (15), 3551-3556.

30. Langmuir, I., The adsorption of gases on plane surfaces of glass, mica and platinum. J. Am. Chem. Soc. 1918, 40, 1361-1403.

31. Freundlich, H., Concerning adsorption in solutions. Zeitschrift Fur Physikalische Chemie-Stochiometrie Und Verwandtschaftslehre 1906, 57, (4), 385-470.

32. Dubinin, M. M.; Zaverina, E. D.; Serpinsky, V. V., The sorption of water vapour by active carbon. Journal of the Chemical Society 1955, 1760-1766.

33. Temkin, M.; Pyzhev, V., Kinetics of ammonia synthesis on promoted iron catalysts. Acta Physicochimica Urss 1940, 12, (3), 327-356. 
34. Karthik, R.; Meenakshi, S., Chemical modification of chitin with polypyrrole for the uptake of $\mathrm{Pb}(\mathrm{II})$ and Cd(II) ions. Int. J. Biol. Macromol. 2015, 78, 157-164.

35. Omraei, M.; Esfandian, H.; Katal, R.; Ghorbani, M., Study of the removal of Zn(II) from aqueous solution using polypyrrole nanocomposite. Desalination 2011, 271, (1), 248-256.

36. Xu, Z.; Wang, K.; Liu, Q.; Guo, F.; Xiong, Z.; Li, Y.; Wang, Q., A bifunctional adsorbent of silica gel-immobilized Schiff base derivative for simultaneous and selective adsorption of $\mathrm{Cu}(\mathrm{II})$ and $\mathrm{SO}_{4}{ }^{2-}$. Separation and Purification Technology 2018, 191, 61-74.

37. Ali, J.; Wang, H.; Ifthikar, J.; Khan, A.; Wang, T.; Zhan, K.; Shahzad, A.; Chen, Z.; Chen, Z., Efficient, stable and selective adsorption of heavy metals by thio-functionalized layered double hydroxide in diverse types of water. Chemical Engineering Journal 2018, 332, 387-397.

38. Oyetade, O. A.; Skelton, A. A.; Nyamori, V. O.; Jonnalagadda, S. B.; Martincigh, B. S., Experimental and DFT studies on the selective adsorption of $\mathrm{Pb}^{2+}$ and $\mathrm{Zn}^{2+}$ from aqueous solution by nitrogen-functionalized multiwalled carbon nanotubes. Separation and Purification Technology 2017, 188, 174-187.

39. Chen, J.; Feng, J.; Yan, W., Facile synthesis of a polythiophene/ $/ \mathrm{TiO}_{2}$ particle composite in aqueous medium and its adsorption performance for $\mathrm{Pb}(\mathrm{ii})$. RSC Advances 2015, 5, (106), 86945-86953.

40. Li, Y., Conducting Polymers. Springer International Publishing: 2015; p 23-50.

41. Kim, C.-S.; Shin, J.-W.; Cho, Y.-H.; Jang, H.-D.; Byun, H.-S.; Kim, T.-O., Synthesis and characterization of $\mathrm{Cu} / \mathrm{N}$-doped mesoporous $\mathrm{TiO} 2$ visible light photocatalysts. Applied Catalysis A: General 2013, 455, 211-218.

42. Yoshida, T.; Yamaguchi, T.; Iida, Y.; Nakayama, S., XPS Study of $\mathrm{Pb}(\mathrm{II})$ Adsorption on $\gamma-\mathrm{Al}_{2} \mathrm{O}_{3}$ Surface at High pH Conditions. Journal of Nuclear Science and Technology 2003, 40, (9), 672-678.

43. Iaiche, S.; Djelloul, A., $\mathrm{ZnO} / \mathrm{ZnAl}_{2} \mathrm{O}_{4}$ Nanocomposite Films Studied by X-Ray Diffraction, FTIR, and X-Ray Photoelectron Spectroscopy. Journal of Spectroscopy 2015, 2015, 9.

44. Li, Y. F.; Qian, R. Y., Effect of anion and solution ph on the electrochemical-behavior of polypyrrole in aqueous-solution. Synthetic Metals 1989, 28, (1-2), 127-132. 